\title{
Identification of the Factors Affecting the Quality of Education at Secondary School Level Students in Tehsil Faisalabad
}

\author{
Shazia Kausar* \\ Education Department, Government College Women University, Faisalabad \\ Rida Shoukat \\ Education Department, Government College Women University, Faisalabad
}

\begin{abstract}
Every last individual has the fundamental right to education. Without direction no nation will be gaining ground. The training framework in Pakistan is confronting different issues now a days. It is important to analyze the factors that influence the implementation of the students, and to get low or high ratings from the students. The execution of the understudies in scholastic isn't just affected by their own attributes talented by the nature yet in addition different components are associated with these achievements. For the monetary and social improvement of the general public, it is important to give our youngsters the quality training. As of late, the majority of the endeavors have been made to look out the components that influence the student execution. Today, in the age of the revolution of globalization and development, schooling is viewed as a opener for any individual initiative. It performs as a critical act for the advancement of human cardinal and linked with an individual's contentment and convenience for better living. The purpose of this study is to examine and explore those factors that can affect the student's education quality at secondary level. There are many reasons which effects on the student's education like personal causes, institutional causes, family causes, socio-economic causes etc.
\end{abstract}

Keywords: Improvement, learning, factors affecting students' performance, influence

DOI: $10.7176 / \mathrm{JEP} / 11-18-21$

Publication date:June 30th 2020

\section{Introduction}

In this era of information and technological transformation, education for any individual operation is seen as a first step. It plays a crucial role in the creation of human capital and has been related to the well-being and incentives for a person to live better (Battle \& Lewis, 2002). It strengthens the unification of knowledge and skills that allow individuals to increase their productivity and improve the quality of their lives. Higher production also contributes to new sources of income that boost the country's economic growth (Saxton, 2000). For teachers, the consistency of the success of students remains a priority.

For a long time, educators, trainers, and researchers have been keen to explore different factors that effectively procure learners for quality performance. Such factors were inside and outside training, impacting the level of academic achievement of students. Such factors can be defined as factors for students, family factors , school factors and peer factors (Crosnoe et al., 2004). In the 17th century, the systematic inquiry into the position of these demographic factors took root (Mann, 1985). Academic benefit and learning success of students is affected by various consequences including gender, age, teaching facilities, schooling for students, social economic status of guardians and their residents.

These considerations typically include age, class, geographical affiliation, race, marital status, education level of the parents, parental occupation, nationality, income and religious federations. A successful student's education depends heavily on the social status of the parents / guardians in the society (Considine and Zappala, 2002). These are usually examining under the umbrella of demography (Ballatine, 1993). Demography as a means to investigate the existence and consequences of demographic variables in the biological and social sense was discussed in a broader framework.

Unfortunately, identifying and assessing the quality of education is not a easy problem and the difficulty of this task is growing due to the evolving expectations of quality qualities relevant to the various stakeholders' view point (Blevins 2009; Parri 2006).

(Adeyemo, 2001) preached that the genuine target of the school was to work towards the accomplishment of instructive significance through understudies. As showed by him, the school may have other periphery targets anyway emphasis was frequently determined to the execution of sound give. Additionally, fundamentally everybody stressed with guideline places premium on Academic accomplishment; stunning insightful achievement of youths was oftentimes the craving of watchmen.

There were some regular elements influencing scholastic instruction of the understudies were guardians' financial status, student's confirmation point's previous school foundation and scholarly training of understudies. Those segments which impact the scholarly training of understudies. They were; parent's direction in cocurricular activities. 
It was crucial to remember that even these exams did not correlate with the previous exams the study the past achievement affects the potential execution of the understudies in consideration, but that the validation scores were associated with instructive execution at school level to an exceedingly negligible degree. The scores of graduate level investigations still out play out some other single measure of psychological inclination in foreseeing accomplishment at college level.

It was also expected that children knowledge result and enlightening performance were obviously influenced by regular and kind of informational establishing in which substitutes got their preparation. The educational condition of the institute goes to set the restrictions of understudies' education comes to fruition. (Considine and Zappala, 2002) showed that schools' condition and instructor's needs from their option in like way had solid influence on student performance. A large portion of the teachers working in deprived schools or schools having run nervous of principal work environments much of the time had low performance needs from the stores and when understudies comprehend that their teachers have low performance wishes from them, in the future it stimulates poor implementation by the substitutes.

Parental responsibility in a pre-adult's direction close by natural and financial components may affect kid progress in parts, for example, comprehension, language, and social limits. Diverse reviews around there have given the hint. (Crosnoe and Elder, 2004) the school management, game-planning in the workforce and openmindedness of incentives in the classroom is an imperious intrinsic feature of the school. Educational cost-based institutes as a result of better financing, honest to goodness proprietorship, remarkable work force and resources, for instance, PCs perform better than whatsoever government subsidized schools. The additional sponsoring resources and workplaces found in educational cost-based schools overhaul academic indictment and instructive satisfaction of their students.

In this backdrop, this research offers answer to the following research questions:

- To identify the major institutional and socio-economic factors that effects the student's education

- To find out the psychological factors affecting the student's education

- To give recommendations for improving the student's quality of education

\section{Review of Literature}

Instructive managements were frequently not obvious and firm to quantify the grounds that result as shift of information, fundamental abilities and conduct decrease of students (Tsinidou, et al., 2010). So, there no usually limitless supply of worth that was connected to instruction arena. The importance of nature of preparation veer from culture (Michael, 1998). The world and the specific attributes of students assume an essential part in their school's prosperity. The institute work force, beings from the families and groups give sustenance to understudies for the nature of their scholastic execution. This social help had an unequivocal part for activity of execution objectives for understudies at institute (Goddard, 2003). Other than the social construction, guardians' connection in the youngster's training expands the rate of scholastic accomplishment of their kid (Furstenberg \& Hughes, 1995).

Well the other statistic issues, the impact of (SES) Supplemental Educational Services were as yet normal at the specific level (Capraro, M. et al., 2000). The SES considered in various diverse ways; it was frequently computed by taking a gander of parental training, occupation, salary, plus offices utilized by people independently.

(Harb and El-Shaarawi, 2006) initiate the most essential part by valuable outcome of understudies' execution as student's capacity in English. Chance that the surrogate have dense social limits and have solid hold tight English, it develops the release of the understudies. The achievement of the option was influenced by social limits; it was believable to see soundness as variable which might be unequivocally recognized with requirement of the substitute in open education.

The home condition impacts the academic institution of hold. Indicated guards can give such a situation, to the point that suits best for academic exertion of their adolescents. The school powers can give urging and making a beeline for guardians for making positive home condition for development in understudies' disposition of work (Marzano, 2003). The educational execution of understudies genuinely relies upon the parental constancy in their academic exercises to complete the greater measure of critical worth in insightful achievement (Barnard et al., 2004).

Various researchers had been breaking down numerous factors which effects the student's academic execution in their investigation. There were two sorts of factors that affect the understudies' academic implementation. They were inside and outside institutional factors and these parts persistently affect the understudies' accomplishment. Inner institution sections join understudies limit in English, class masterminds, class evaluate, English examining material, class test happens, learning working environments, homework, state of the class, complicated nature of the course material, coaches' part in the class, advancement exploited as bit of the class and exams structures.

Outside classroom components join extracurricular exercises, family issues, work and money related, social 
and differing issues. Get some information about reviews demonstrates that understudies' execution relies upon numerous components, for example, learning work environments, sex and age complexities, and so on that can affect student execution.

(Ahmad and Khan, 2012) researched cash related state of guards puts a remarkable effect upon youngsters' Academic achievement. This review watches the relationship of money related state of the guards and understudies' Academic achievement of government schools for youthful colleagues of region Dir, Timergara Pakistan. The consequences of the review uncovered an essential relationship between the cash related states of overseer and Academic achievement of their kids in assistant exams.it diverted out from the outcomes that the greater part of the understudies whose guards had enhanced money related conditions did marvelous work in their optional exams on the other hand with whose guardians had poor budgetary conditions.

\section{Findings}

Table 1

Ranking of the respondents regarding to the teacher related factors

\begin{tabular}{|c|c|c|c|c|}
\hline Teacher Related Factors & Weighted Score & Rank Order & Mean & S.D \\
\hline Lack of guidance of teachers & 195 & 4 & 1.5 & 3.3 \\
\hline Need for a subject specialist & 169 & 5 & 1.3 & 3.2 \\
\hline Teachers favoritism & 156 & 6 & 1.2 & 3.4 \\
\hline Shortage of trained teachers & 585 & 1 & 4.5 & 3.4 \\
\hline Teachers' behaviour & 156 & 7 & 1.2 & 3.3 \\
\hline Less grip of teachers in English & 286 & 3 & 2.2 & 3.3 \\
\hline Teach according to students' mentality & 143 & 8 & 1.1 & 3.2 \\
\hline Teachers punishment & 156 & 7 & 1.2 & 3.3 \\
\hline Lack of appreciation from teachers & 351 & 2 & 2.7 & 3.4 \\
\hline
\end{tabular}

*S.D: Standard Deviation

The data observed in Table 1 pointed out about the teacher related factors affects the students' performance, top ranking was given to such respondents' shortage of trained teachers with a weighted score of 585, mean as 4.5 and having the standard deviation valued as 3.4. The $2^{\text {nd }}$ ranking was that the respondents' lack of appreciation from teachers with a weighted score of 351, mean as 2.7 and having the standard deviation valued as 3.4. The $3^{\text {rd }}$ ranking was about the less grip of teachers in English with a weighted score of 286, mean as 2.2 and having the standard deviation esteemed as 3.3.

The $4^{\text {th }}$ ranking was that the lack of guidance of teachers with a weighted score of 195 , mean as 1.5 and having the standard deviation valued as 3.3 . The $5^{\text {th }}$ ranking was that the need for a subject specialist with a weighted score of 169 , mean as 1.3 and having the standard deviation recorded as 3.2 . The $6^{\text {th }}$ ranking was the teachers' favoritism with a weighted score of 156, mean as 1.2 and having the standard deviation valued as 1.4. The $7^{\text {th }}$ ranking was about the teacher's punishment resulting a weighted score of 156 , mean as 1.2 and having the standard deviation valued as 3.3. The $8^{\text {th }}$ ranking was that the respondents with teaching according to the student's mentality resulting a weighted score of 143 , mean as 1.1 and having the standard deviation founded as 3.2 .

The data above reflected that majority of the respondents apparent that shortage of trained teachers and lack of appreciation from teachers are the teacher related factors affecting their performance. Most of the respondents also apparent that less grip of teachers in English and lack of guides by teachers also affects the academic performance.

In a comparable study, as indicated by (Telli, 2013) educators were the most basic operators for guaranteeing nature of instruction was accomplished inside and outside classrooms. Also, putting educators and learning at the focal point of training was a critical advance in propelling exchanges and securing arrangement consideration. 
Table 2.

Ranking of the respondents regarding to their examination related factors

\begin{tabular}{|c|c|c|c|c|}
\hline Examination Related Factors & Weighted Score & Rank Order & Mean & S.D \\
\hline Examination center facilities & 403 & 4 & 3.1 & 1.4 \\
\hline Distance of examination center & 442 & 1 & 3.4 & 2.8 \\
\hline Atmosphere and weather effects & 403 & 5 & 3.1 & 1.3 \\
\hline Paper formation as for student ratios & 403 & 6 & 3.1 & 1.2 \\
\hline Examiner is quite strict & 442 & 2 & 3.4 & 1.3 \\
\hline Students noise & 442 & 3 & 3.4 & 1.2 \\
\hline Paper is out of course & 377 & 8 & 2.9 & 1.4 \\
\hline Lack of concentration & 390 & 7 & 3.2 & 1.3 \\
\hline
\end{tabular}

The data represented in Table 2 pointed out about the examination related factors affects the students' performance, top ranking was given to distance of examination center with a weighted score of 442, mean as 3.4 and having the standard deviation valued as 2.8 . The $2^{\text {nd }}$ ranking was that the examiner is quite strict with a weighted score of 442 , mean as 3.4 and having the standard deviation valued as 1.3 . The $3^{\text {rd }}$ ranking was about the students' noise with a weighted score of 442, mean as 3.4 and having the standard deviation esteemed as 1.2.

The $4^{\text {th }}$ ranking was the examination center facilities with a weighted score of 403 , mean as 3.1 and having the standard deviation valued as 1.4 . The $5^{\text {th }}$ ranking was atmosphere and weather effects with a weighted score of 403 , mean as 3.1 and having the standard deviation recorded as 1.3 . The $6^{\text {th }}$ ranking was that the paper formation as for student ratio with a weighted score of 403, mean as 3.1 and having the standard deviation valued as 1.2. The $7^{\text {th }}$ ranking was that the respondents with lack of concentration resulting a weighted score of 390 , mean as 3.0 and having the standard deviation valued as 1.3 . The $8^{\text {th }}$ ranking was that the respondents with paper is out of course resulting a weighted score of 377, mean as 2.9 and having the standard deviation founded as 1.4 .

The data above represented that widely held of the respondents apparent that distance of examination center and examiner is quite strict are the examination related factors affecting their performance. Most of the respondents also apparent that students' noise and examination center facilities also affects the academic performance.

In an equivalent study, (Juma, 2011) joins execution in examinations to condition of educating and learning assets in schools. He saw that understudies from poor foundations perform deficiently in the examinations in light of how the poor were routinely in achieves where schools were truly kept from securing fundamental work environments, a mentality of weakness might be indicated appropriate on time into adolescent influencing them to feel that being in school was a futile movement.

Table 3.

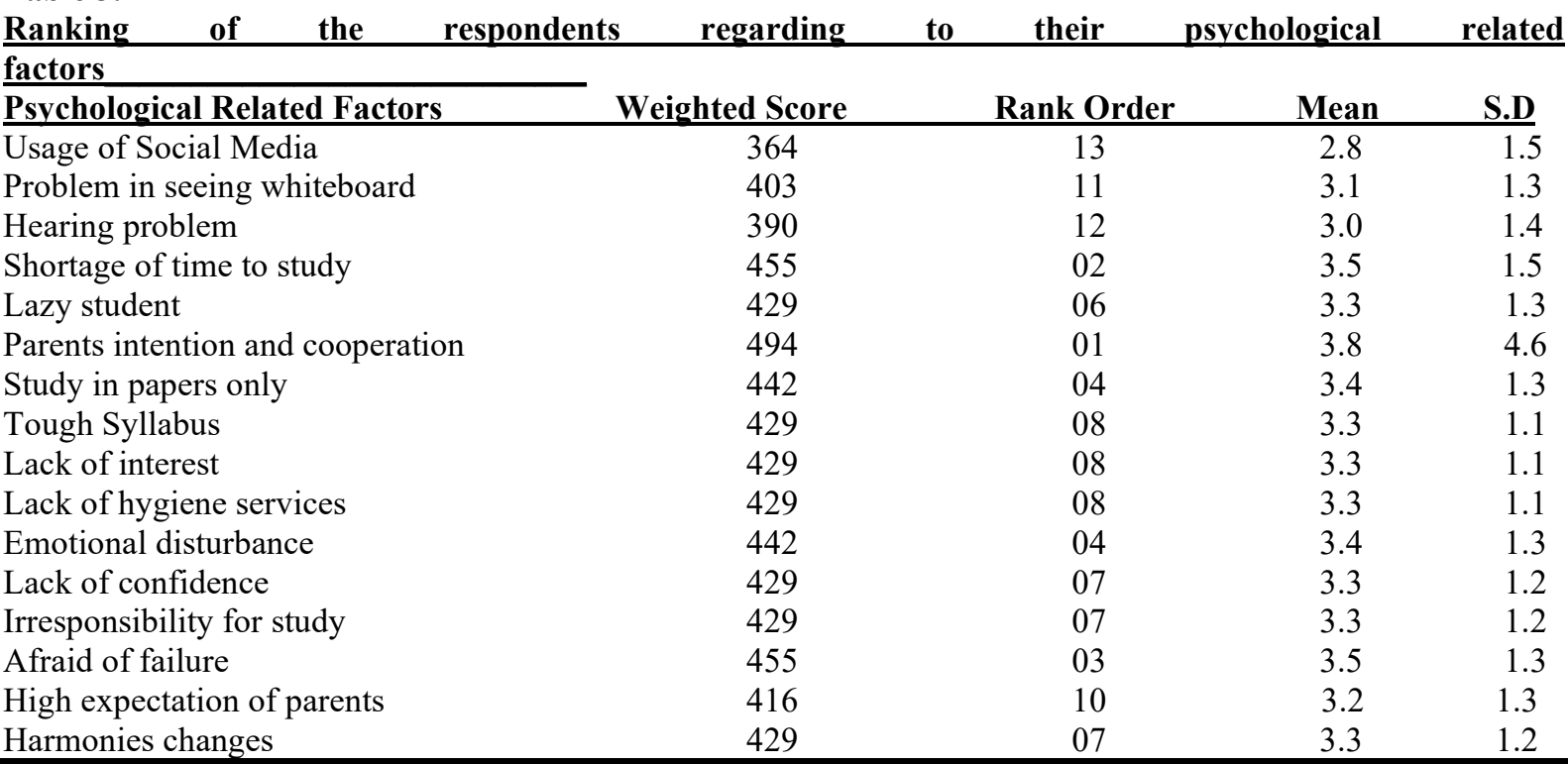

The data identified in Table 3 pointed out about the psychological factors affects the students' performance, top ranking was given to such respondents' parent intention and cooperation with a weighted score of 494, mean as 3.8 and having the standard deviation valued as 4.6. The $2^{\text {nd }}$ ranking was that the respondents' shortage of time to study with a weighted score of 455 , mean as 3.5 and having the standard deviation valued as 1.5 . The $3^{\text {rd }}$ ranking was about the respondents' afraid of failure with a weighted score of 455 , mean as 3.5 and having the 
standard deviation valued as 1.3 . The $4^{\text {th }}$ ranking was the respondents' study in papers only with a weighted score of 442 , mean as 3.4 and having the standard deviation founded as 1.3 .

The 5th ranking was about the respondent's tough syllabus with a weighted score of 429, mean as 3.3 and having the standard deviation valued as 1.4. The 6th ranking as the lazy students with a weighted score of 429 , mean as 3.3 and having the standard deviation recorded as 1.3. The 7th ranking was that the respondents with harmonies changes, irresponsibility for study and emotional disturbance resulting a weighted score of 429 , mean as 3.3 and having the standard deviation valued as 1.2. The 8th ranking was the respondents with lack of interest resulting a weighted score of 429 , mean as 3.3 and having the standard deviation esteemed as 1.2. The 9th ranking was the respondents with lack of confidence resulting a weighted score of 416, mean as 3.2 and having the standard deviation valued as 1.4.

The 10th ranking as the respondents with high expectation of parents resulting a weighted score of 416 , mean as 3.2 and having the standard deviation measured as 1.3. The 11th ranking as the respondents with problem in seeing white board resulting a weighted score of 403, mean as 3.1 and having the standard deviation valued as 21.3. The 12th ranking as hearing problem resulting a weighted score of 416 , mean as 3.0 and having the standard deviation valued as 1.4. The 13th ranking as usage of social media resulting a weighted score of 364 , mean as 2.8 and having the standard deviation esteemed as 1.5 .

The data above represented that majority of the respondents perceived that parent's intention and cooperation and shortage of time to study are the psychological related factors affecting their performance. Most of the respondents also perceived that afraid of failure and lack of hygiene services also affects their academic performance.

In a similar study, (Ballatine, 1993) found that segments combine age, genderual presentation, topographical belongingness, ethnicity, conjugal status, money related status, parent's preparation level, parental calling, tongue, pay and religious affiliations. These were generally examined under the umbrella of demography.

Table 4.

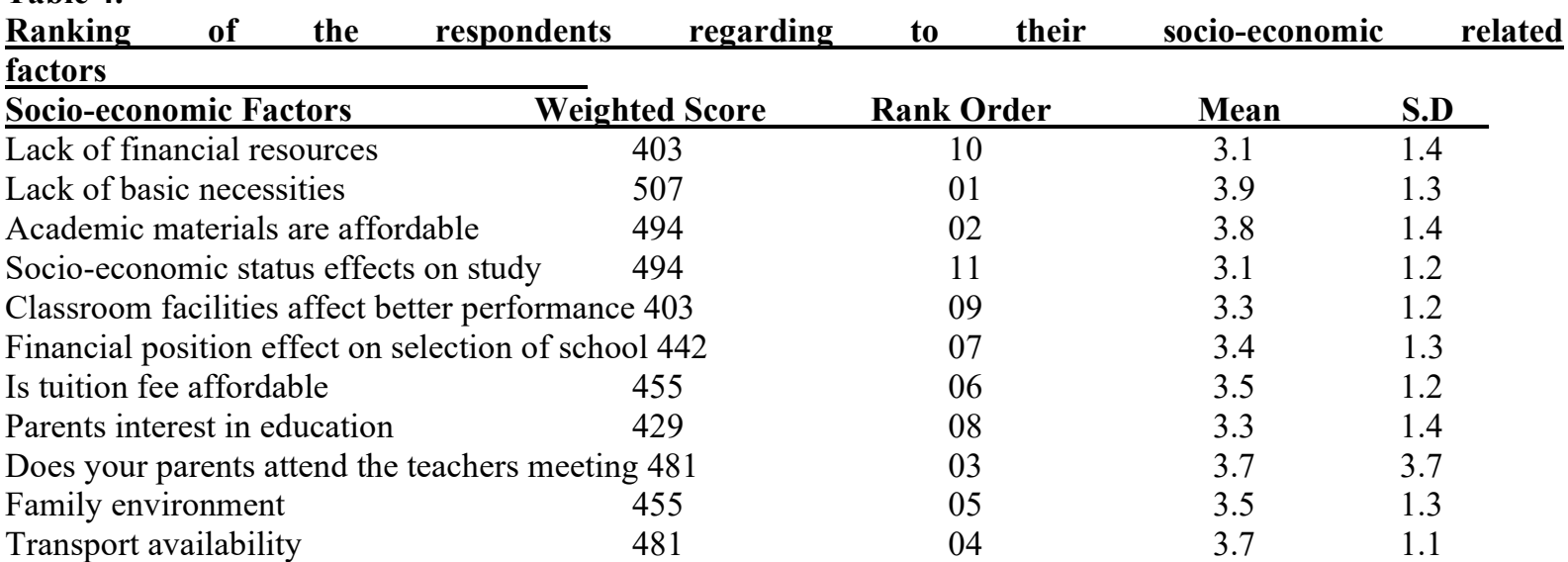

The data reflected in Table 4 pointed out about the socio-economic factors affects the students' performance, top ranking was given to such respondents who lack of basic necessities with a weighted score of 507, mean as 3.9 and having the standard deviation valued as 1.3 . The $2^{\text {nd }}$ ranking was that the respondents' academic material are affordable with a weighted score of 494 , mean as 3.8 and having the standard deviation valued as 1.4 . The $3^{\text {rd }}$ ranking was that the respondents' parents attend the teachers meeting with a weighted score of 481, mean as 3.7 and having the standard deviation valued as 3.7. The $4^{\text {th }}$ ranking was that the respondents transport availability with a weighted score of 481 , mean as 3.7 and having the standard deviation valued as 1.1 . The $5^{\text {th }}$ ranking was that the respondent's family environment with a weighted score of 455 , mean as 3.5 and having the standard deviation valued as 1.3 .

The $6^{\text {th }}$ ranking was that the respondent's tuition fee affordable with a weighted score of 455 , mean as 3.5 and having the standard deviation valued as 1.2. The $7^{\text {th }}$ ranking was that the respondents financial position effect on selection of the school resulting a weighted score of 442, mean as 3.4 and having the standard deviation valued as 1.3 . The $8^{\text {th }}$ ranking was that the respondent's parents' interest in education resulting a weighted score of 429 , mean as 3.3 and having the standard deviation valued as 1.4 . . The $9^{\text {th }}$ ranking was that the respondent's classroom facilities affect the better performance resulting a weighted score of 429 , mean as 3.3 and having the standard deviation valued as 1.2 . The $10^{\text {th }}$ ranking was that the respondents lack of financial resources resulting a weighted score of 403, mean as 3.1 and having the standard deviation valued as 1.4.

The $11^{\text {th }}$ ranking was that the respondents' socio-economic status effects on your study resulting a weighted score of 403, mean as 3.1 and having the standard deviation valued as 1.2. The data above represented that widely held of the respondents apparent that distance of examination center and examiner is quite strict are the examination related factors affecting their performance. Most of the respondents also apparent that students' 
noise and examination center facilities also affects the academic performance.

In a similar study, (Dynarski, 2003, 2008 and Scott-clayton, 2011) noted that tuition fees can have an impact on student effort both through affecting incentives and by creating financial constraints. The latter is mainly relevant in U.S. context where financial constraints can limit the possibility to continue studying and/or complete a study program which eventually affects the quality of education attained.

\section{Discussion}

Teacher related factors affects the student performance

- Majority of the respondents apprehend the shortage of trained teachers, lack of appreciation from teachers and less grip of teachers in English as the common factors that affect their performance.

- Lack of guidance of teachers, need for a subject specialist and teachers' favoritism are also considered by the respondents as the factors that affect the students' academic performance.

- Some of the respondents also apprehend that teachers' punishment and teaching according to the students' mentality were also relative to affect their performance.

Examination related factors affects the student performance

- Distance of examination center, examiner is quite strict, and students' noise were the top ranked perceived factors that affect the students' performance.

- Most of the respondents also perceived that examination center facilities, atmosphere and weather effects and paper formation according to the student ratio also affects the students' academic performance.

- Regarding factors, lack of concentration and paper is out of course also affecting the students' performance in school.

Psychological related factors affects the student performance

- Majority of the respondents comprehend that parents' intention and cooperation, shortage of time to study, afraid of failure and lack of hygiene services were the important factors that affect the academic performance.

- Tough syllabus, lazy students, emotional disturbance with irresponsibility of study and harmonies changes, lack of interest and lack of confidence were also considered as the common factors affecting their performance in schools.

- Some of the students also conclude as high expectation of parents, problem in seeing the white board, hearing problem and usage of social media as the factors affecting students' performance.

\section{Socio-economic related factors affects the student performance}

- Lack of basic necessities, academic material is affordable, parents' attendance in teacher meeting and transport availability were the top ranked factors perceived by the respondents affecting their academic performance.

- Most of the respondents also perceived that family environment, tuition fee affordable, financial position effect on the selection of school and parents' interest in education as the common factors that affect their performance in school.

- Regarding factors, classroom facilities affect the better performance, lack of financial resources and socio-economic status effects on the studies as affecting their academic performance.

\section{Conclusion}

While identifying the factors that affects the quality of education at secondary school level. There were some important factors in this research that reported by respondents were these including parents' cooperation, better facilities and home environment, hygiene environment and better teaching staff and appreciation from teachers and parents. Respondents reported that if they were able to attain full cooperation and concentration of their parents, they could improve their quality of education. Majority of the students also reported that if poverty and quarreled soreness of parents removed from their life, they all perform better in the study. Most of the respondents also agreed with institutional facilities that hygiene environment with better teaching staff and management will also remove the hurdles in their study and improve the efficiency in studies. With better family support and teachers support, students can able to overcome their psychological issues that affect their academic performance.

(Raychanduri et al., 2010) sections like interest in the class, family wage, moms and fathers preparing, instructor student degree, closeness of organized teachers in schools, sexual introduction of understudies and segment of school were likewise affected the execution of the understudies.

\section{References}

Adeyemo, D. A. (2001). Teachers' job satisfaction, job involvement, career and organizational commitments as 
correlates of student-academic performance. Nigerian Journal of Applied Psychology, 6 (2), 126-135.

Ahmed and Khan, T.M. (2012). Education and National Development in Nigeria. Journal of Studies in Education. 10:35-46

Battle, J., \& Lewis, M. (2002). The increasing significance of class: The relative effects of race and socioeconomic status on academic achievement. Journal of Poverty, 6(2), 21-35.

Ballatine, J. H. (1993). The sociology of education: A systematic analysis. Englewood Cliffs: Prentice Hall.

Blevins, B. M. (2009). Effects of socioeconomic status on academic performance in Missouri public schools. Retrieved from http://gradworks.umi.com/3372318.pdf

Barnard, W. M. (2004). Parent involvement in elementary school and educational attainment. Children and Youth Services Review, 26, 39- 62

Capraro, M. M., Capraro, R. M., \& Wiggins, B. B. (2000). An investigation of the effect of gender, socioeconomic status, race and grades on standardized test scores. Southwest Educational Research Association, Dallas, TX.

Crosnoe, R., Johnson, M. K., \& Elder, G. H. (2004). School size and the interpersonal side of education: An examination of race/ethnicity and organizational context. Social Science Quarterly, 85(5), 12591274.

Considine, G. and G. Zappala (2002), "Factors influencing the educational performance of students from disadvantaged backgrounds', in T. Eardley and $B$.

Dynarski, Susan (2003). "The Behavioral and Distributional Implication of Aid for College." Manuscript prepared for AER Papers and Proceedings, 2002.

Dynarski, Susan (2008). "Does Aid Matter? Measuring the Effect of Student Aid on College Attendance and Completion." Kennedy School of Government Working Paper.

Goddard, R. D. (2003). Relational networks, social trust, and norms: A social capital perspective on student's chances of academic success. Educational Evaluations \& Policy Analysis, 25, 59-74.

Harb, Nasri and El-Shaarwi, Ahmed. (2006). 'Factors Affecting Student's Performance'. Journal of Business Education, Vol. 82, No. 5 (2007): pp. 282-290.

Juma, F. (2011). The Relationship between mode of Teacher Motivational and students' Academic performance in Public Secondary Schools in Bungoma North District. Unpublished M.Ed. Project Report, Moi University, Kenya.

Marzano, R. J. (2003). What works in schools: Translating research into action? Retrieved from http://pdonline.ascd.org/pd_online/whatworks/marzano2003_c h13.html

Mann, M. (1985). Macmilan student's encyclopedia of sociology. England: Anchor Brendon Ltd.

Michael, S.O. (1998). Restructuring US higher education: Analyzing models for academic program review and discontinuation. The Review of Higher Education, 21(4), 377-404.

Parri, J. (2006). Quality in higher education. Vadyba/Management, 2(11),107-111.

Raychaudhuri, A., M. Debnath., S. Sen, and B.G Majunder, (2010). Factors affecting Students' academic performance: A case study in agartala municipal conical area. Bangladesh e-journal of sociology, vol.7, Number 2 .

Saxton, J. (2000). Investment in education: Private and public returns. Retrieved from http://www.house.gov/jec/educ.pdf.

Tsinidou, M., Gerogiannis, V., \& Fitsilis, P. (2010). Evaluation of the factors that determine quality in higher education: an empirical study. Quality Assurance in Education, 18(3), 227-244.

Telli, G. (2013). How Should Quality of Education Be Re-Defined for Education Achievements in Tanzania? What Are Stakeholders' Opinions? Journal of International Education and Leadership Volume, 3(1). 